\title{
Article
}

\section{In Vivo Evaluation of PVP-Gelatin-Chitosan Composite Blended with Egg-Yolk Oil for Radiodermatitis}

\author{
Yi-Chi Hung ${ }^{1,2,3}$, Shu-Chih Hsieh ${ }^{4}$, Syuan-Ren Hou ${ }^{1,5}$, Jui-Yin Kung ${ }^{1,6}$, Cheng-Ming Tang $7,8, * \mathbb{D}$ \\ and Chen-Jung Chang ${ }^{1,9, *}$
}

1 Department of Medical Imaging and Radiological Science, Central Taiwan University of Science and Technology, Taichung 40601, Taiwan; ychuang0620@gmail.com (Y.-C.H.); x752623127@gmail.com (S.-R.H.); jykung@vghtc.gov.tw (J.-Y.K.)

2 Department of Radiology, Kaohsiung Veterans General Hospital, Kaohsiung 813414, Taiwan

3 Department of Medical Imaging and Radiology, Shu-Zen Junior College of Medicine and Management, Kaohsiung 82144, Taiwan

4 Department of Chemical and Materials Engineering, National Chin-Yi University of Technology, Taichung 40724, Taiwan; shiehsj@ncut.edu.tw

5 Department of Radiation Oncology, E-Da Hospital, Kaohsiung 824410, Taiwan

6 Department of Nuclear Medicine, Taichung Veterans General Hospital, Taichung 40705, Taiwan

7 Graduate Institute of Oral Science, Chung Shan Medical University, Taichung 40201, Taiwan

8 Department of Dentistry, Chung Shan Medical University Hospital, Taichung 40201, Taiwan

9 Animal Radiation Therapy Center, Central Taiwan University of Science and Technology, Taichung 40601, Taiwan

* Correspondence: ranger@csmu.edu.tw (C.-M.T.); jrchang@ctust.edu.tw (C.-J.C.); Tel.: +886-4-2239-1647 (ext. 7101) (C.-J.C.); Fax: +886-4-2239-6762 (C.-J.C.)

Citation: Hung, Y.-C.; Hsieh, S.-C.; Hou, S.-R.; Kung, J.-Y.; Tang, C.-M.; Chang, C.-J. In Vivo Evaluation of PVP-Gelatin-Chitosan Composite Blended with Egg-Yolk Oil for Radiodermatitis. Appl. Sci. 2021, 11 10290. https://doi.org/10.3390/ app112110290

Received: 30 July 2021

Accepted: 27 October 2021

Published: 2 November 2021

Publisher's Note: MDPI stays neutral with regard to jurisdictional claims in published maps and institutional affiliations.

Copyright: (c) 2021 by the authors Licensee MDPI, Basel, Switzerland. This article is an open access article distributed under the terms and conditions of the Creative Commons Attribution (CC BY) license (https:/ / creativecommons.org/licenses/by/ $4.0 /)$.

\begin{abstract}
Radiation-induced skin injury (RSI) is a frequent complication of radiotherapy. Severe cases affect the patient's disease treatment and quality of life. The main purpose of this study is to examine the causative role of egg-yolk oil (EYO) in delayed radiation-induced skin injury, including impaired wound healing. Using polyvinyl pyrrolidone (PVP)-gelatin-chitosan (PGC) composite film as controlled release of egg-yolk oil (EYO) was studied in rats, which were used as a radiation-induced skin injury model. Different composition ratios were tested for their mechanical properties, moisture content, and degradation characteristics. The results showed that the PGC112 $(w / w)$ substrate, which will hence be referred to as PGC, had the better properties. Further, the PGC was mixed with EYO (0.25\% and 0.5\%) to prepare the films (PGC/0.25EYO and PGC/0.5EYO, respectively). Furthermore, the mechanical and degradation properties and biocompatibility showed better results with PGC/0.5EYO. In animal studies, rats were irradiated with single-dose electron beams of $40 \mathrm{~Gy}$. The animals were divided into five groups to perform wound treatment with various types of wound dressing for 30 days. Histological examination and CD68 immunochemical staining were then conducted, and observations were made. The results showed that PGC/0.5EYO has a significantly healing effects on radiodermatitis and good re-epithelialization.
\end{abstract}

Keywords: chitosan; gelatin; polyvinylpyrrolidone; egg-yolk oil; radiodermatitis; wound healing; biodegradation; biocompatibility

\section{Introduction}

Radiotherapy is a cancer treatment, often employed for breast cancer, head and neck cancer, and cervical cancer, that uses high doses of ionizing radiation to destroy cancer cells or to shrink the tumor. However, radiodermatitis can easily appear on radiation-sensitive skin when it is high-energy radiation penetrated. Clinically, 95\% of cancer patients receiving radiotherapy will develop some form of radiodermatitis [1]. Up to $85 \%$ of patients will have moderate to severe inflammation. Acute inflammation mostly occurs from the first week to the fourth week of radiotherapy and causes capillary dilation and damage, dermal 
endothelial cell mutation, mass inflammatory cell infiltration, and tissue necrosis [2-4]. Serious cases often recover only after two to four weeks, or even longer after therapy has concluded. In clinical care, moist skin care with 3\% urea lotion delays the occurrence and reduces the grade of acute skin reactions in percutaneously irradiated patients with head and neck tumors [5]. A previous study has demonstrated that patients who used urea cream for radiotherapy aftercare had a $50 \%$ lower chance of developing radiodermatitis compared to the control group [6]. In contrast, aloe vera gel is widely used in clinical care due to its low-cost and wide availability [7]. Compared to aqueous cream, aloe vera gel is beneficial for reducing the identified skin side-effects of radiotherapy [8]. However, there are no drugs or products that are guaranteed to prevent dermatitis.

Wound dressings are also a suitable option during the aftercare process. D'haese et al., noted a gradual increase in the clinical use of hydrophilic dressings with tight seals, which not only provide a good setting for dry desquamation and moist desquamation care, but also promote cell growth and migration [3]. In contrast with traditional dry wound repair methods, mock-natural extracellular matrix (ECM)-based biomedical materials as wound dressings can act as a support for promoting cell growth by creating environments similar to those inside the body for in vitro cells [9]. These dressings provide a moist environment so that the cells involved in tissue repair, such as fibroblasts and epithelial cells, can migrate quickly and proliferate, thus promoting wound healing while absorbing copious amounts of the interstitial fluid produced during wound repair.

Biomedical materials based on blends of polymers made from different materials not only provide the benefits of these polymers, but also improve physical properties. In addition to facilitating cell repair by acting as a shield that protects an injured area as well as helping the skin to recover its normal functions, a good dressing can also absorb the interstitial fluid discharged during wound repair, which can also be absorbed by the body during fibrous tissue degradation. Gel-based dressings can also act as drug carriers for fabricating long-lasting functional dressings with decent restorative effects for injured areas. Furthermore, polyvinyl pyrrolidone (PVP), chitosan, and gelatin have been widely used in the study of wound dressings [10-12]. PVP is a water-soluble, biodegradable, synthetic polymer. Due to its excellent biocompatibility, PVP has been used in numerous biomedical applications, such as implants, drug delivery devices [13], and wound dressings [14]. However, PVP is an amphiphile substances. It produces strong hydrogen bonding with chitosan and gelatin. PVP combined with gelatin can increase solution viscosity and is helpful for the production of films and hydrogels [11,12]. PVP and chitosan have previously been mixed into a film to improve the mechanical properties of the film and increase its water vapor permeability and antibacterial properties [10]. A PVP and chitosan composite hydrogel showed dual properties by supporting the growth of epithelial cells (SiHa) and selectively inhibiting fibroblast (NIH3T3) growth. The mechanical strength and hydrophilicity of the composite was higher than pure chitosan membrane. These findings point to the possible use of chitosan-PVP hydrogels in chronic wound-management [15]. Chitosan is a derivative of deacetylated chitin and has excellent hemostatic properties due to its ability to form cationic clusters that can interact with the anions of red blood cells, thus inducing platelet aggregation [16]. Gelatin has excellent characteristics such as low antigenicity and good biocompatibility and biodegradability. Gelatin can activate platelet aggregation and is also used as an absorbable hemostatic agent [17]. Gelatin has previously been mixed with many types of biopolymers to enhance its chemical stability and mechanical properties. Chitosan has amido groups and can coordinate and cross-link with gelatin. Chitosan/gelatin composite has been shown to have better hemostatic effects in rabbit artery bleeding and liver model tests, liquid absorption, and platelet aggregation than chitosan and gelatin alone [18].

Egg-yolk oil (EYO) is extracted by refining cooked egg yolks. EYO contains unsaturated fatty acids, saturated fatty acids, fat-soluble vitamins, phospholipids, and cholesterol. It has been used as a traditional medicine in China for more than a thousand years. The first record of EYO treatment for burns and scalds was found in "Set Prescription", dated 
around $500 \mathrm{AD}$, and it was also recorded in the famous "Compendium of Materia Medica", written during the Ming Dynasty [19]. Currently, EYO is widely used to treat all kinds of burn wounds. Rastegar et al., applied EYO in the treatment of third-degree burns in rats and showed abundant re-epithelialization without tissue scarring in comparison with silver sulfadiazine treatment groups [20]. Zhao et al., identified the hemostatic function of EYO. Coagulation assays suggested that EYO stimulates the intrinsic blood coagulation system and activates the fibrinogen system [21]. Moreover, lecithin in EYO is negatively charged and binds with positively-charged polymers; while electrostatic repulsion stabilizes an emulsion and prevents the emulsified oil droplets from coalescing and attaining oil-water separation [22]. Therefore, lecithin can be used in the emulsification and blending of hydrophobic drugs and hydrophilic polymers and is often blended with chitosan. Yenilmez et al., applied chitosan-based gels mixed with EYO to enhance the local treatment of dermal burns and found that these mixtures had excellent restorative effects [23]. Rodil et al., found that EYO is helpful for 3T3 fibroblast adhesion and growth [24]. The purpose of this study is to create a hydrogel-like film by combining EYO with PGC composite film so as to evaluate its properties, biocompatibility, and the ability of EYO in repairing radiation dermatitis wounds through in vivo experiments.

\section{Materials and Methods}

\subsection{Preparation of PVP-Gelatin-Chitosan (PGC) Composite Film}

The polyvinyl pyrrolidone (PVP, molecular biology grade, M.W. 360,000 g/mol) used in this study was obtained from Scientific Polymer Products (Ontario, NY, USA). Gelatin (type A from porcine skin, 300 Bloom) was obtained from Sigma-Aldrich (St. Louis, MO, USA). A low molecular weight chitosan was also supplied by Sigma-Aldrich (St. Louis, MO, USA) with $75-85 \%$ of deacetylation degree. PVP, gelatin, and chitosan were dissolved in different weight ratios in $2 \%$ acetic acid aqueous solution (see Table 1). The PGC solution was placed on a magnetic stirrer until it was dissolved completely at room temperature. The solution was evenly poured onto a Teflon plate, and an automatic film applicator was used to form a $2.8 \mathrm{~mm}$-thick film on the plate. The films were crosslinked in the glutaraldehyde vapor at room temperature for $15 \mathrm{~min}$. After crosslinking, the films were dried at $110^{\circ} \mathrm{C}$ for $30 \mathrm{~min}$ and were then vacuum freeze-dried to remove glutaraldehyde and acetic acid residues.

Table 1. Grouping of animal experiment for radiation dermatitis.

\begin{tabular}{|c|c|}
\hline Group & Description \\
\hline Blank & No treatment \\
\hline Control & $\begin{array}{l}\text { The dressing and, from inside to outside, } 3 \mathrm{M}^{\mathrm{TM}} \text { Tegaderm }{ }^{\mathrm{TM}} \text { transparent film dressing and sterilized } \\
\text { breathable dressing, gauze, elastic bandage, and mesh bandage, respectively. }\end{array}$ \\
\hline EYO & $\begin{array}{l}\text { Wrap EYO and, from inside to outside, } 3 \mathrm{M}^{\mathrm{TM}} \text { Tegaderm }{ }^{\mathrm{TM}} \text { transparent film dressing and sterilized } \\
\text { breathable dressing, gauze, elastic bandage, and mesh bandage, respectively. }\end{array}$ \\
\hline PGC112 & $\begin{array}{l}\text { Wrap PGC112 film and, from inside to outside, } 3 \mathrm{M}^{\mathrm{TM}} \text { Tegaderm }{ }^{\mathrm{TM}} \text { transparent film dressing and } \\
\text { sterilized breathable dressing, gauze, elastic bandage, and mesh bandage, respectively. }\end{array}$ \\
\hline PGC/0.5EYO & $\begin{array}{l}\text { Wrap PGC/0.5EYO film and, from inside to outside, } 3 \mathrm{M}^{\mathrm{TM}} \text { Tegaderm }{ }^{\mathrm{TM}} \text { transparent film dressing and } \\
\text { sterilized breathable dressing, gauze, elastic bandage, and mesh bandage, respectively. }\end{array}$ \\
\hline
\end{tabular}

\subsection{Preparation of PGC/EYO Composite Film}

Egg-yolk oil (EYO) is extracted by refining cooked egg yolks by supercritical carbon dioxide; the production process also complies with current good manufacture practices (cGMP) specifications. EYO was added to the PGC solution at different ratios $(0.25 \%$ and $0.5 \%$ ) (Table 2 ) and emulsified by homogenizer (T25 digital ULTRA-TURRAX ${ }^{\circledR}$, IKA, Staufen, Germany) at 10,000 rpm for $1 \mathrm{~min}$. The above solution was coated onto a Teflon plate via an automatic film applicator to form a $2.8 \mathrm{~mm}$-thick film. The films 
were crosslinked in the glutaraldehyde vapor at room temperature for $15 \mathrm{~min}$. After crosslinking, the films were dried at $110{ }^{\circ} \mathrm{C}$ for $30 \mathrm{~min}$ to remove glutaraldehyde and acetic acid residues.

Table 2. Composition and characterization of PGC films.

\begin{tabular}{ccccccc}
\hline Sample & PVP & Gelatin & Chitosan & Water Content (\%) & Young's Modulus (MPa) & Tensile Strength (MPa) \\
\hline PGC112 & 1 & 1 & 2 & $92.8 \pm 0.1$ & $927 \pm 13$ & $62.3 \pm 2.2$ \\
PGC122 & 1 & 2 & 2 & $91.8 \pm 0.3$ & $907 \pm 24$ & $51.8 \pm 1.7^{*}$ \\
\hline
\end{tabular}

*: Smaller than the other sample $(p<0.05)$.

\subsection{Physicochemical Characterization of Composite}

2.3.1. Surface Morphology

The surface morphologies of PGC and PGC/EYO composite films were examined by a field emission scanning electron microscope (FESEM) (JSM-7100F, JEOL, Tokyo, Japan). Samples were dried in vacuum at room temperature for $24 \mathrm{~h}$ and coated with gold before examination.

\subsubsection{Chemical Analysis}

Fourier transform infrared (FTIR) spectroscopy was used to characterize the changes in specific functional groups. FTIR spectra were obtained by a Thermo Nicolet $380 \mathrm{spec}-$ trometer (Waltham, MA, USA) in the spectral range of $400-4000 \mathrm{~cm}^{-1}$ and a resolution of $4 \mathrm{~cm}^{-1}$, scanning 64 time.

\subsubsection{Water Content Ratio}

The dry films were pre-cut to a fixed size and weighed $\left(W_{0}\right)$. Pre-weighted films were immersed in $10 \mathrm{~mL} 0.9 \%$ saline solution for $24 \mathrm{~h}$. Afterwards, the films were rinsed and the excessive water on the surface was removed with filter paper and the fully swollen samples were again weighed $\left(W_{1}\right)$. Water content ratios were calculated using the following equations: Water content ratio $(\%)=\left[W_{1}-W_{0}\right] / W_{1} \times 100 \%$.

\subsubsection{Mechanical Properties}

The tensile properties of films were measured by a universal testing machine (GF-AI7000M, GO TECH, Taichung, Taiwan) using a low force load cell of $10 \mathrm{~N}$ capacity. Samples were immersed in phosphate buffer solution (PBS) for $2 \mathrm{~min}$ to achieve complete swelling. The swelling samples were then cut with a dumb-bell-shaped die of length $40 \mathrm{~mm}$ and width $20 \mathrm{~mm}$. The thickness of each sample was measured by a micrometer with an accuracy of $1 \mu \mathrm{m}$. Sponge tape was applied onto the ends of the samples prior to loading to enhance the ends for gripping, and they were then clamped with $4.94 \mathrm{kN}$ fixtures. The strain was measured by two extensometers mounted on the surface of the sample. The measured gauge length of the extensometer was $20 \mathrm{~mm}$. The measurement was performed at a crosshead speed of $10 \mathrm{~mm} / \mathrm{min}$. The tensile strength and Young's modulus were calculated based on the generated tensile stress-strain curve.

\subsubsection{Degradation Rate}

The dry films were pre-cut to a fixed size and weighed $\left(W_{0}\right)$. The samples were then immersed in $10 \mathrm{~mL}$ phosphate buffered saline (PBS) solution and cultured at $37^{\circ} \mathrm{C}$. The samples were taken out and rinsed with deionized water after soaking for one day, three days, and seven days. The samples were freeze dried for $24 \mathrm{~h}$ and weighted $\left(W_{1}\right)$. The degradation rate of the films was calculated based on the following equation: degradation rate $(\%)=\left[W_{0}-W_{1}\right] / W_{0} \times 100 \%$.

\subsection{Biocompatibility}

A mouse-derived fibroblasts cell line (L929) was maintained in minimum essential media (MEM) and supplemented with $10 \%$ fetal bovine serum (FBS) at $37^{\circ} \mathrm{C}$ in a $5 \% \mathrm{CO}_{2}$ 
incubator. In addition, the film extraction in this study followed the ISO 10993-12 standard. All samples were cut into square shapes $\left(3 \mathrm{~cm}^{2}\right)$ and sterilized with UV radiation for $6 \mathrm{~h}$ and immersed in $1 \mathrm{~mL}$ of MEM without phenol red at $37^{\circ} \mathrm{C}$ in a $5 \% \mathrm{CO}_{2}$ incubator. After $72 \mathrm{~h}$ extraction periods, the film extract solution was obtained. The cell suspension with a cell density of $1 \times 10^{4}$ cells $/ \mathrm{mL}$ were seeded into 96-well culture plates for $72 \mathrm{~h}$. Extract solutions were seeded into culture plates, followed by culturing for 24 and $72 \mathrm{~h}$ at $37^{\circ} \mathrm{C}$ in a $5 \% \mathrm{CO}_{2}$ incubator. After incubation, samples were rinsed with PBS, followed by incubation in a culture medium containing $0.05 \mathrm{~mL}$ MTT reagent for $4 \mathrm{~h}$. After removal of the medium, $0.1 \mathrm{~mL}$ of dimethyl sulfoxide (DMSO) was added to the wells. An amount of $0.1 \mathrm{~mL}$ from each sample solution was transferred to 96-well plates, and the optical density (OD) was measured at $570 \mathrm{~nm}$.

\subsection{In Vivo Study}

\subsubsection{Animals and Experimental Design}

Thirty healthy adult male Sprague Dawley (SD) rats (BioLASCO Taiwan Co., Ltd., Taipei, Taiwan; 7 weeks of age, with average body weight of $250 \pm 20 \mathrm{~g}$ ) were used. Ambient temperature was kept at $25 \pm 2{ }^{\circ} \mathrm{C}$ during the experiments. All animal experiments were carried out according to the protocol approved by the animal experimentation committee at the Central Taiwan University of Science and Technology (Taichung, Taiwan) (Approve number: 107-CTUST-011). The rats were divided randomly into 5 equal-sized groups (6 rats per group), namely, Blank group (untreated wound), Control group ( $3 \mathrm{M}^{\mathrm{TM}}$ Cavilon ${ }^{\mathrm{TM}}$ no-sting barrier films were applied as dressings), EYO group (EYO films were applied), PGC112 group (PGC112 films were applied), and PGC/0.5EYO group (PGC/EYO films containing 0.5\% EYO). An Elekta linear accelerator (Precise ${ }^{\mathrm{TM}}$, Lund, Sweden) with $6 \mathrm{MeV}$ of nominal energy and dose rate of $400 \mathrm{cGy} / \mathrm{min}$ was used to induce the skin damage. The rats were anesthetized and sedated by Zoletil $50^{\circledR}(40 \mathrm{mg} / \mathrm{kg})$ (Virbac Animal Health, Carros, France). The hair over the dorsum was clipped and the skin was scrubbed with $75 \%$ ethanol solution. Rats were given full anesthesia through flowing isoflurane and irradiated with single-dose electron beams of $40 \mathrm{~Gy}$. The distance between the irradiation source and the rat was $100 \mathrm{~cm}$. The irradiation field was $6 \times 6 \mathrm{~cm}^{2}$, located at the shaved region, and a bolus of $1 \mathrm{~cm}$ was used in order to deposit the maximum percentage depth dose onto the skin. After $6 \mathrm{~h}$ of irradiation, the skin of the rats was cleaned with saline solution and dressed with dressings that corresponded to the groupings listed in Table 1 . The degree of skin injury was observed at intervals of 3 days for 30 days.

\subsubsection{Analysis of the Wound Area of Radiodermatitis}

On the twelfth day after irradiation, radiodermatitis wounds were observed. On 15, 21 , and 30 days after irradiation, rat wound status was recorded using a digital singlelens reflex camera (EOS 70D, Canon, Tokyo, Japan). The wound area was calculated by ImageJ software.

\subsubsection{Histological Analysis}

At 12 and 30 days after irradiation, the rats were sacrificed by methoxy-fluorane overdose, and the irradiated tissue was excised up to the subcutaneous layer. The excised tissues were fixed in 10\% neutral buffered formalin for $8 \mathrm{~h}$ and transferred to $70 \%$ ethanol before paraffin embedding and sectioning. For immunohistochemistry staining of CD68, sections were pre-treated using heat mediated antigen retrieval with sodium citrate buffer (pH6, epitope retrieval solution 1) for $30 \mathrm{~min}$. The section was then incubated with CD68 (ab125212, Abcam, Cambridge, UK) for $15 \mathrm{~min}$ and detected using a horseradish peroxidase conjugated compact polymer system. Diaminobenzidine was used as the chromogen for $10 \mathrm{~min}$. The section was then counterstained with hematoxylin and mounted with dibutyl phthalate in xylene (DPX). The stained sections were analyzed using a light microscope and images captured by a digital camera (COOLPIX 995, Nikon Co., Tokyo, Japan). Images of the histological sections were digitized and subsequently analyzed using ImageJ software. 


\subsection{Statistical Analysis}

All data were expressed as mean \pm standard deviation (SD) from five repeat samples. The data were analyzed using JMP 13 software (Statistics Analysis System, Cary, NC, USA). A one-way ANOVA followed by a Tukey's HSD post hoc test was used to determine the level of significance, where $p<0.05$ was considered to be significant.

\section{Result and Discussion}

\subsection{Characterization of PGC Composite Films}

FTIR spectra analyses were performed to confirm the chemical nature of the PGC films. The FTIR spectrum of chitosan, gelatin, PVP, and PGC composite film can be seen in Figure 1. In spectra of chitosan showed characteristic bands at approximately $1629.6 \mathrm{~cm}^{-1}$, $1556.3 \mathrm{~cm}^{-1}$, and $1407.9 \mathrm{~cm}^{-1}$, corresponding to amides I, amides II, and vibrations of -OH groups, respectively. A broad peak at $3278.6 \mathrm{~cm}^{-1}$ was found, indicating stretching vibration due to the $\mathrm{N}-\mathrm{H}$ and $\mathrm{O}-\mathrm{H}$ bonds. In addition, the spectrum of gelatin shows some characteristic bands around $3280.5 \mathrm{~cm}^{-1}, 1633.5 \mathrm{~cm}^{-1}, 1535.1 \mathrm{~cm}^{-1}$, and $1240.1 \mathrm{~cm}^{-1}$, corresponding to amides $\mathrm{A}$, amide-I, amide-II, and amide-III, respectively. The spectra of PVP shows characteristic bands at $1656.6 \mathrm{~cm}^{-1}$, which corresponds to the stretching vibration of the $\mathrm{C}=\mathrm{O}$ group, and the apparent absorption peak at $1276.7 \mathrm{~cm}^{-1}$ is attributed to the stretching vibration of C-N. The spectra of the PGC composite shows a peak at $1550.6 \mathrm{~cm}^{-1}$, which is the $\mathrm{C}=\mathrm{N}$ functional group produced by gelatin and chitosan through glutaraldehyde cross-linking.

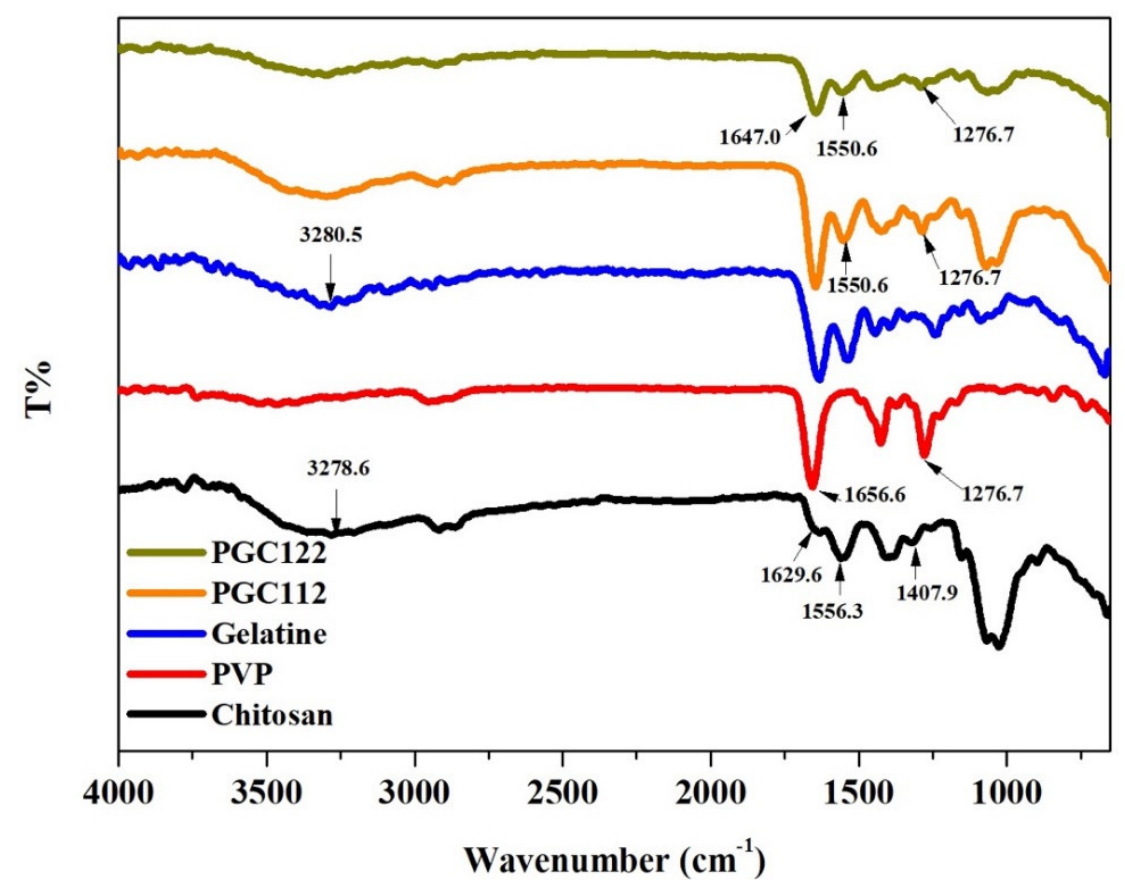

Figure 1. FT-IR spectrum of chitosan, PVP, gelatin, and PGC composite films.

The ideal wound dressings should be soft, firm, and be able to retain their structure such that they do not degrade rapidly due to excess swelling from absorbing large amounts of body fluid. The water content of PGC composite films is showed in Table 2. The water content of each group is higher than $90 \%$, and the PGC111 film is smaller than the other sample. Because gelatin and chitosan molecules contain hydrophilic groups, the content of gelatin and chitosan in the PGC111 film is significantly lower than that of the other groups. Therefore, hydrogen bonding between the water molecules is also reduced. The mechanical properties of PGC111 and PGC121 swollen films are so weak that they broke at the beginning of the tensile test, so mechanical property data could not be obtained (data 
not shown). In another study, the CS film had a Young's modulus of $1.92 \mathrm{GPa}$. When $50 \%$ of PVP is added into CS, the Young's modulus decreases [25]. When the hydrogel-like material is in the swelling state, the Young's modulus will also decrease. In our study, the Young's modulus of the PGC materials is also similar. Another approach is to chemically cross-link chitosan (CS) and boost its mechanical stability without subsuming the baleful chemicals involved in utilizing oxidized polysaccharides. Oxidized cellulose (OC) was subsumed with CS. The inclusion of 5\% OC (relative to CS's weight) into CS films escalated their tensile strength from 51.9 to $74.7 \mathrm{MPa}$ [26]. In our study, The PGC films were crosslinked in glutaraldehyde vapor at room temperature for $15 \mathrm{~min}$. Compared with the above literature data, the increasing trend of the tensile strength of the film is similar.

In addition, gelatin can absorb up to five to ten times its weight in water [27]. Therefore, the content of gelatin in the PGC composite film will affect its mechanical properties and weight loss in PBS. When the gelatin content in the PGC film is increased, the water content of each group (PGC112 and PGC122) shows no significant difference. However, due to the hydrophilic nature of the PGC122 film, it shows a greater swelling property than the PGC112 film. Therefore, the tensile strength and weight loss of the PGC122 film is significantly decreased (Figure 2). Based on the above result, the PGC112 film has a higher water content ratio and tensile strength, as well as a slow degradation rate and is therefore suitable for use as a base material for wound dressings.

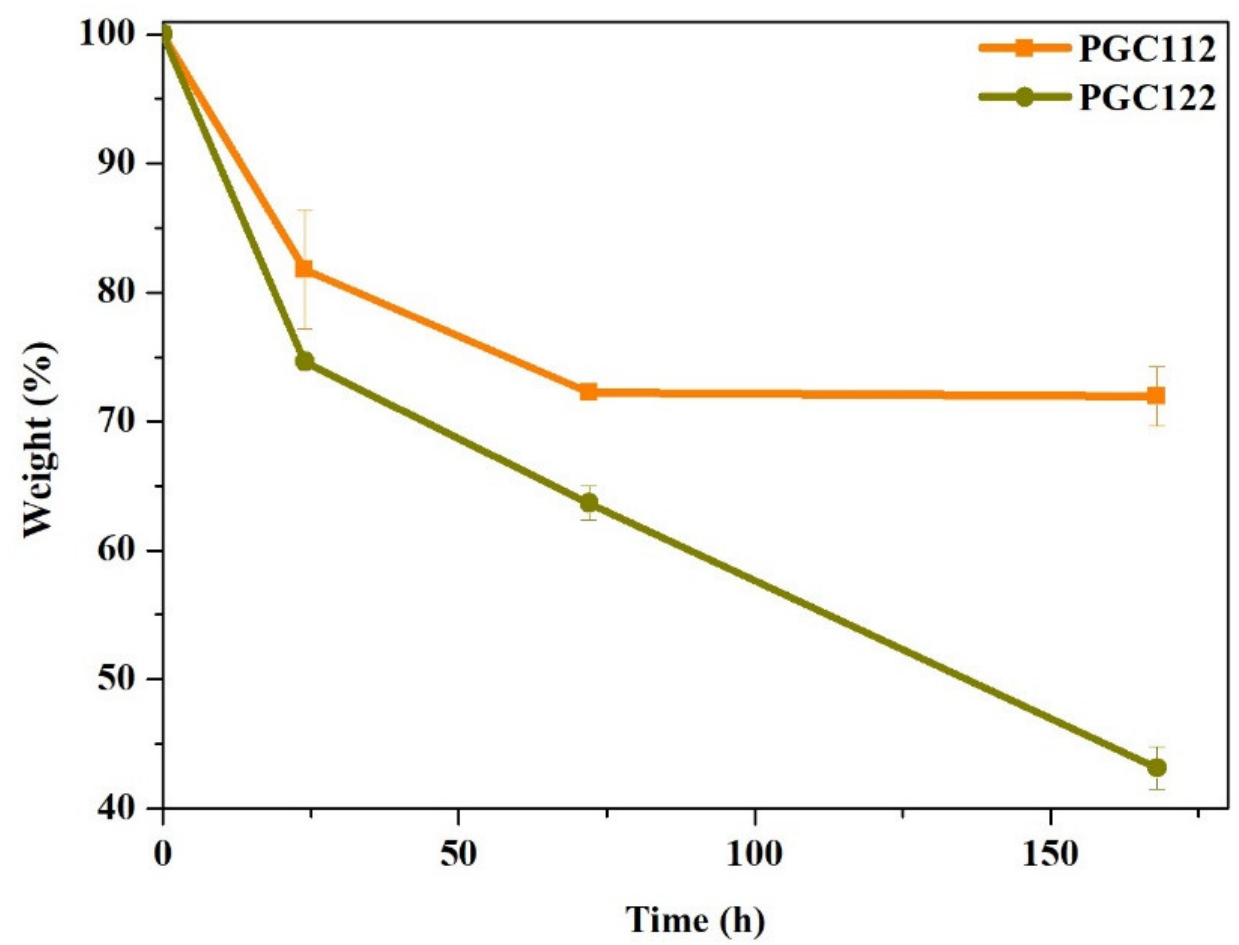

Figure 2. Weight remaining ratio of PGC composites in PBS at $37^{\circ} \mathrm{C}$.

\subsection{Characterization of PGC/EYO Composite Films}

In this study, by adding EYO to the dressings, it is expected that the lecithin, unsaturated fatty acids, and vitamins in the oils can assist in cell regeneration. However, oils have a great impact on the properties of a dressing by altering its softness, firmness, and elongation. The surface of the PGC112 film was observed to be flat and smooth (Figure 3). The surfaces of the PGC/EYO films revealed that their surfaces were rough, uneven, and contained particles with varying diameters. The distribution and particle size of EYO particles increased in response to higher EYO ratios. This is because emulsified EYO droplets tend to collide with each other and agglomerate during emulsification, thus increasing the particle size [6]. The average size of PGC/0.25EYO is $4.6 \pm 1.7 \mu \mathrm{m}$ and PGC/0.5EYO is 
$4.9 \pm 1.4 \mu \mathrm{m}$. The resuls show that particle size was increased following EYO inclusion on the film.

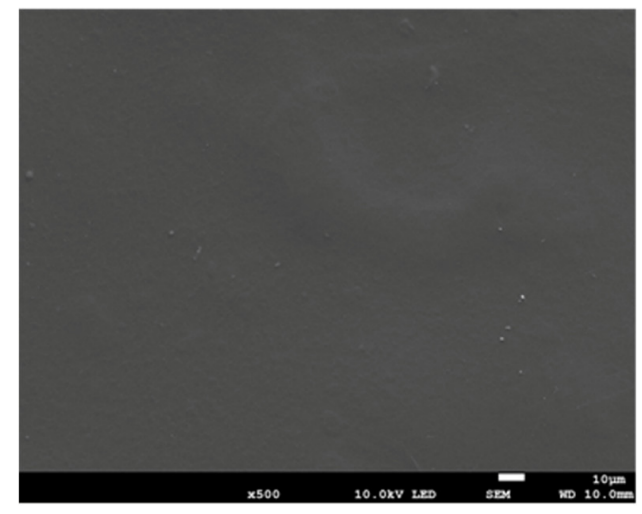

(a)

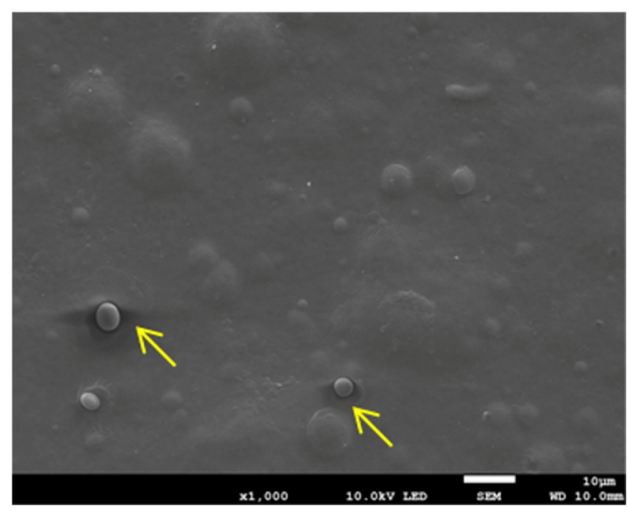

(b)

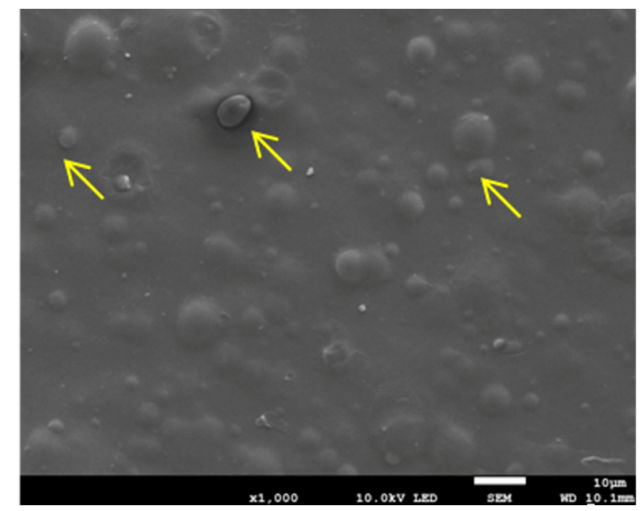

(c)

Figure 3. Surface morphology of (a) PGC112, (b) PGC/0.25EYO, and (c) PGC/0.5EYO composite films by field emission scanning electron microscope (FESEM). The yellow arrow indicates the position where the EYO particles are dispersed.

The FTIR spectrum of the PGC112 and PGC/EYO composite film can be seen in Figure 4. It is apparent that after incorporation of EYO into the PGC112 film, the predominant broad absorption at $3297.8 \mathrm{~cm}^{-1}$ shifted to a higher wavenumber region of $3328.7 \mathrm{~cm}^{-1}$ in the PGC/EYO0.5 film. This band is associated with the $\mathrm{OH}$ stretching of PVP. Because egg-yolk lecithin has a large amount of hydroxyl groups at $3200-3600 \mathrm{~cm}^{-1}$ [28], it may strongly interact with the macromolecular chains of PVP, causing a blue shift. In addition, the spectrum of the PGC/EYO composites shows a new characteristic peak at $1744 \mathrm{~cm}^{-1}$. This represents the $\mathrm{C}=\mathrm{O}$ stretch band of esters in the EYO. However, as the content of EYO increases, the $\mathrm{C}-\mathrm{H}$ stretching vibrations at $1600 \mathrm{~cm}^{-1}$ also increase, though the water content and mechanical properties of the PGC112 and PGC/EYO films show no significant difference (Table 3). The degradation tests of the PGC and PGC/EYO composites show that the weight loss ratio is up to $30 \%$ within one week, and the addition of EYO has no effect on the degradation (Figure 5). 


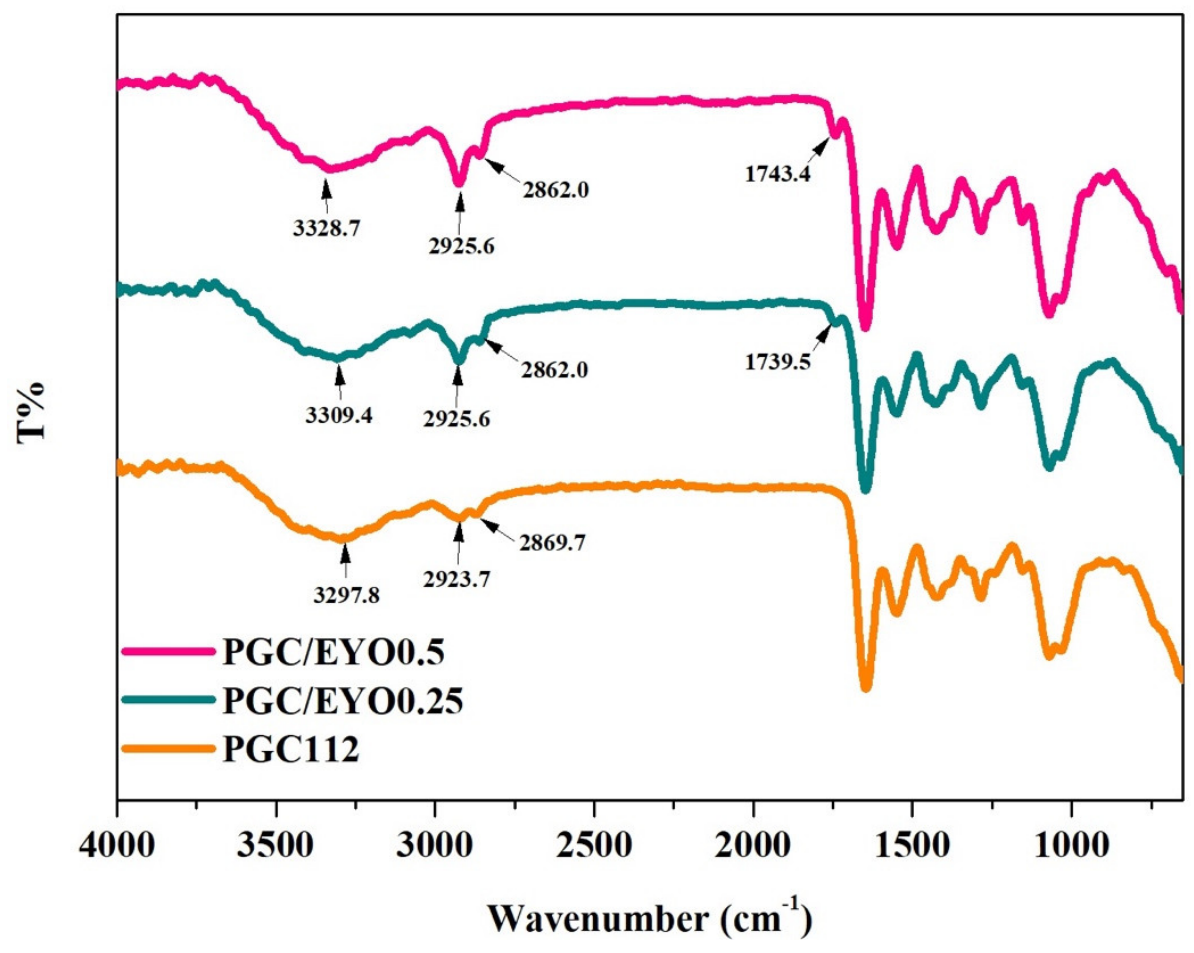

Figure 4. FT-IR spectrum of PGC and PGC/EYO composite films.

Table 3. Composition of PGC/EYO films and characterization.

\begin{tabular}{ccccc}
\hline Sample & EYO (wt) & Water Content (\%) & Young's Modulus (MPa) & Tensile Strength (MPa) \\
\hline PGC112 & 0 & $92.8 \pm 0.1$ & $927 \pm 13$ & $62.3 \pm 2.2$ \\
PGC/0.25EYO & 0.25 & $92.9 \pm 0.3$ & $878 \pm 26$ & $66.8 \pm 2.6$ \\
PGC/0.5EYO & 0.5 & $93.8 \pm 0.9$ & $963 \pm 105$ & $67.2 \pm 4.3$ \\
\hline
\end{tabular}

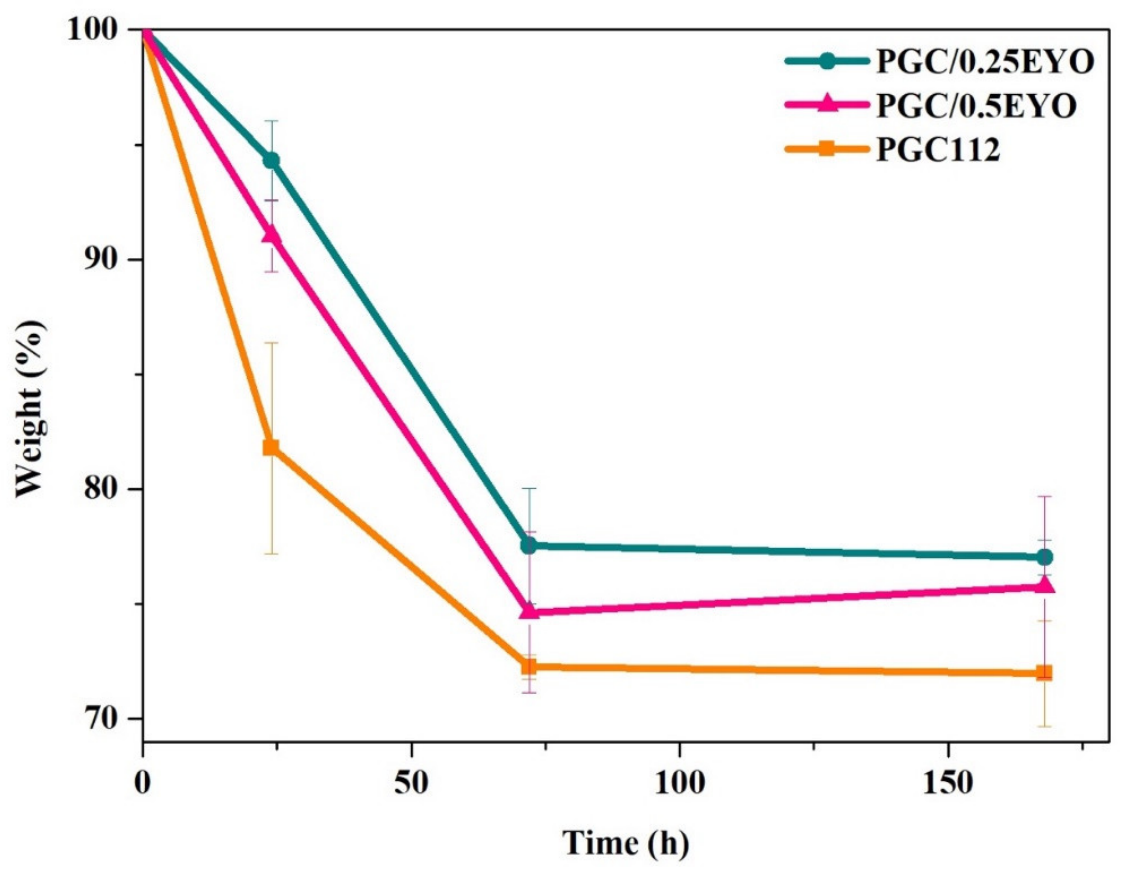

Figure 5. Weight remaining ratios of PGC and PGC/EYO composites in PBS at $37^{\circ} \mathrm{C}$. 


\subsection{Biocompatibility of PGC/EYO Composite Films}

Biocompatibility is implemented in accordance with ISO-10993-5 specifications. The results of the biocompatibility test on the first and third days is show in Figure 6 . The cell survival rate of each group was higher than that of the Control group (tissue culture plate, TCP). The three groups of PGC112, PGC/0.25EYO, and PGC/0.5EYO on the first day after culture all showed a very significant cell proliferation response. As the proportion of EYO increased, the proportion of cell proliferation increased compared to the Control group and were $115 \%, 123 \%$, and $127 \%$, respectively. PGC112 continued to grow by $4 \%$ on the third day of culture; the value-added was $119 \%$, but the PGC/0.25EYO and PGC/0.5EYO groups both dropped to $117 \%$. The above results show that PGC film or PGC/EYO film is non-cytotoxic and contributes to cell proliferation $[15,18]$. Hahn et al., used an EYOmedium mixture treated with sonication to culture HaCaT-cells (immortalized human keratinocytes) and human endothelial cells (HUVEC). The result was found that EYO acts through the reduction of inflammatory processes and ROS production [29]. It can support cell repair and migration and shows potential development for the early acceleration of wound closure.

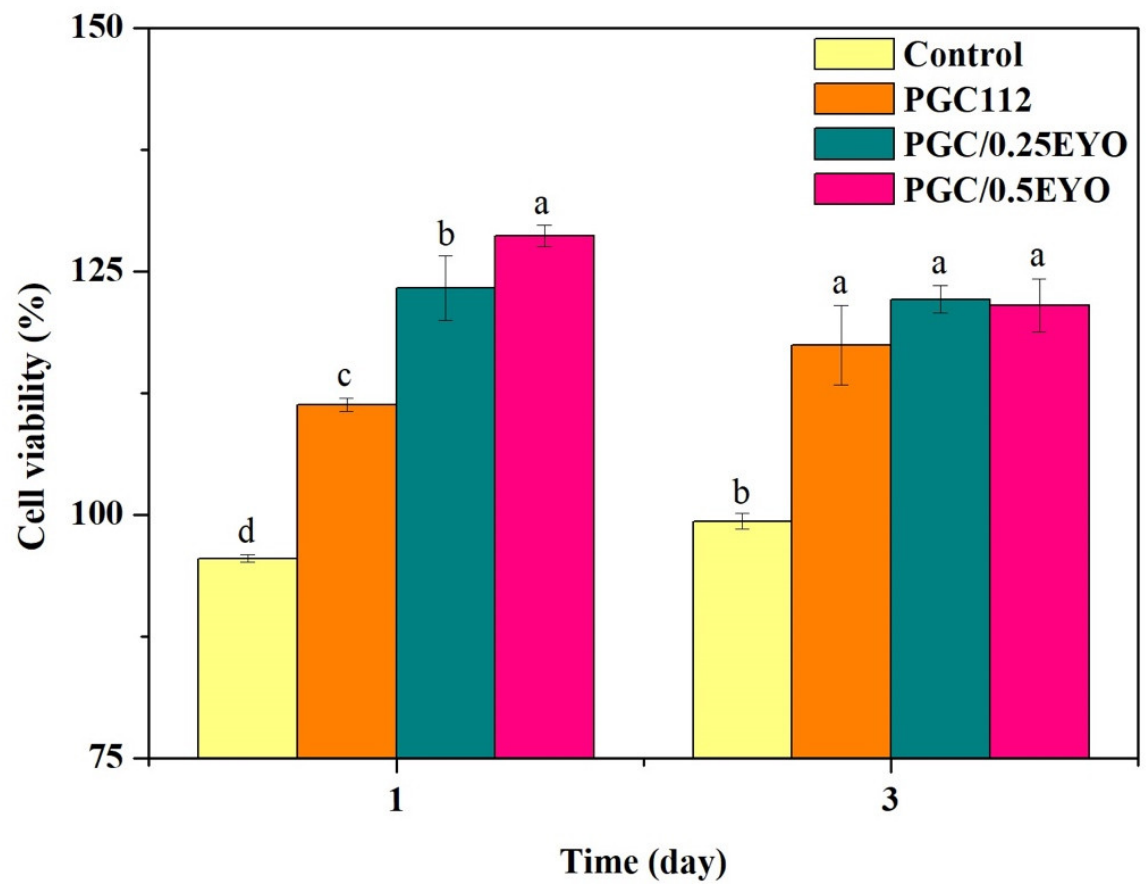

Figure 6. Cell viability performance of mouse fibroblasts cultured with film extract on day 1 and day 3. Means with different letters were significantly different $(p<0.05$, mean $\pm \mathrm{SD}, n=5)$.

\subsection{In Vivo Evaluation}

During the experiment period, the animals had no physical discomfort or weight loss caused by radiation. However, the animals began to show signs of hair loss and redness on the 12th day, and the wounds varied in size and appeared irregular (Figure 7a). All rats had obvious open wounds between day 6 and day 15. At the same time point, $83.7 \%$ of the rats in the EYO group had wounds, and most of them showed mild to moderate hair loss and redness, without large open wounds. In the PGC112 group, 50\% of the rats had wounds, which were mild to moderate depilation accompanied by small open wounds. Only $33.4 \%$ of the PGC $/ 0.5$ EYO group had wounds. The wound area caused by radiation dermatitis in each group was quantified (Figure $7 \mathrm{~b}$ ). As a result, it can be seen that the use of dressing can significantly reduce the wound area compared with the Blank group. Of them all, the PGC/0.5EYO group had the most obvious effect. By the timing of the radiation dermatitis and the size of the wound area, our study found that the Blank group 
and the Control group could not delay the time of radiation dermatitis wounds. The Control group could inhibit the increase of the wound area, but the effect of repairing and reducing the third-degree radiation dermatitis was limited. Shaw et al., also found that the use of $3 \mathrm{M}^{\mathrm{TM}}$ Cavilon ${ }^{\mathrm{TM}}$ painless skin retention film in clinical breast cancer patients can delay the later appearance of itching on the skin, but there was no significant difference in the time of first occurrence of radiation dermatitis compared with the Control group [30]. On the other hand, Yenilmez et al., used EYO mixed with chitosan to treat burn wounds in rats, and it showed an extremely significant repair effect on the 21st day [23]. In our study, the same result was found in the EYO group, maybe because EYO itself has lecithin with hydrophilic and hydrophobic ends, which can keep the irradiated area moisturized and have an antioxidant capacity [29]. In addition, the time of greatest wound area occurrence differed significantly between the PGC films used. Regardless of EYO addition, rats treated with the PGC films had a smaller wound area and exhibited significant differences on the 15 th day compared to other groups. However, the wound area became larger subsequently, with the greatest wound area occurring on the 21st day, which later repaired swiftly. This shows that the PGC films were able to delay the development of radiodermatitis wounds. In particular, the PGC dressings combined with EYO not only delayed wound occurrence, but also offered better alleviative and restorative effects for radiodermatitis wounds.

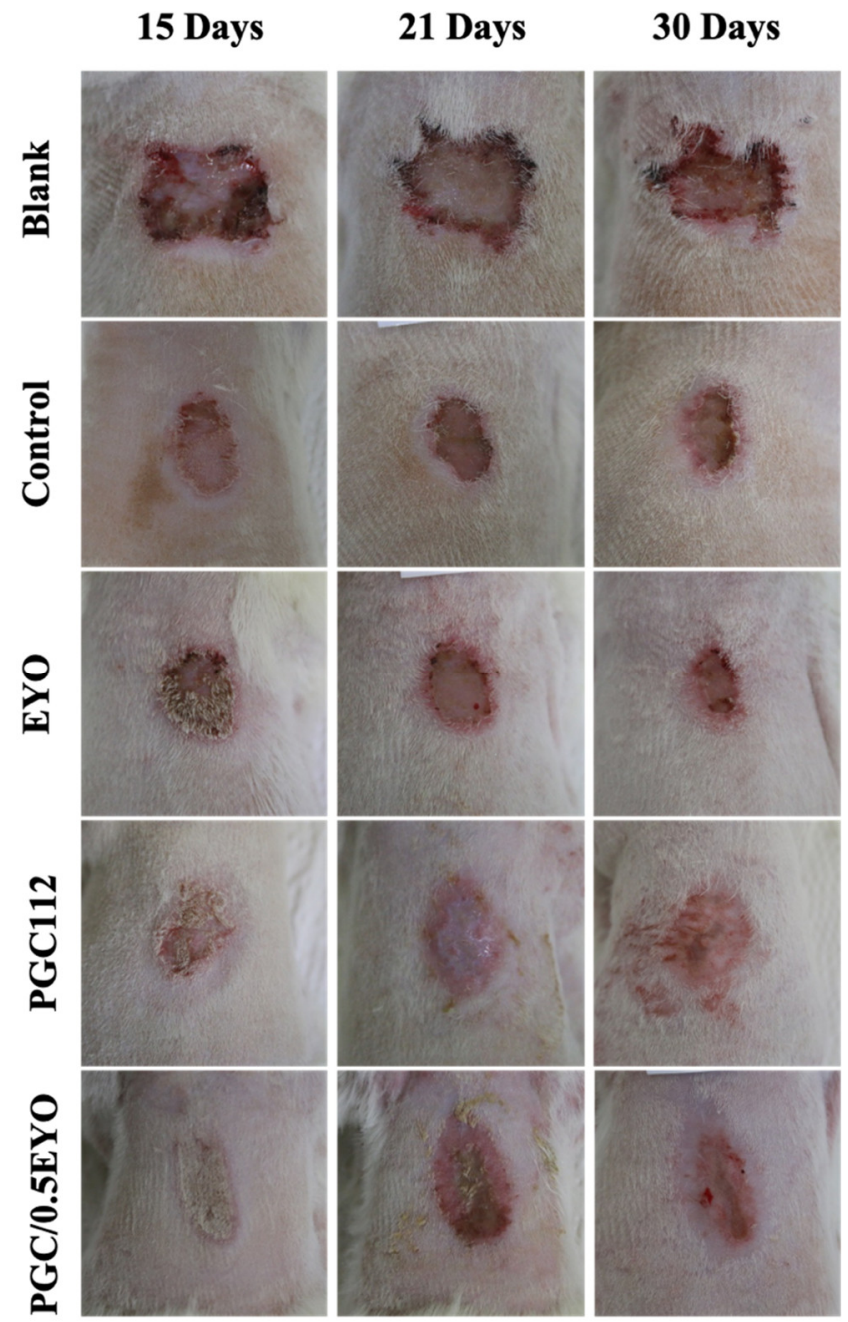

(a)

Figure 7. Cont. 


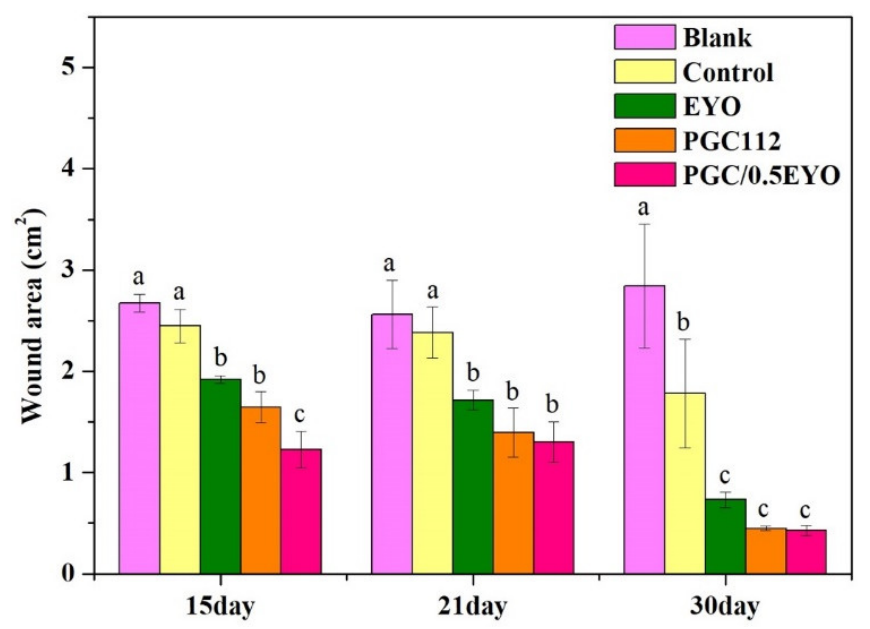

(b)

Figure 7. (a) Macroscopic images of radiation dermatitis wound in rats; (b) Comparison of dermatitis area in each group. Means with different letters were significantly different $(p<0.05$, mean $\pm S D$, $n=5)$.

\subsubsection{Histological Examination}

Histological examinations showed that, in the micrographs of the Blank group (no treatment applied), severe damages in the excised wound sites were detected after 21 days and 30 days, respectively. In the Control group, there was preliminary epithelial tissue growth on the 21st day. The wound surface was still accompanied by necrotic tissue and thicker scabs. Vasodilation was also clearly visible. No skin receptors or hair follicles were found to grow. There was no complete development on the 30th day. After epithelialization, necrotic tissue and thickened dermal tissue could still be seen (Figure 8). Recalling the findings of Shaw et al., who reported that the $3 \mathrm{M}^{\mathrm{TM}}$ Cavilon ${ }^{\mathrm{TM}}$ no-sting barrier films mainly protect the irradiation site against friction from fabrics and were able to delay the occurrence of pruritus, steroids and other anti-inflammatory drugs should be used for the treatment of hyperemia and damaged tissue [30].

The wound scabs in the EYO group were less than those in the Blank group and the Control group. The growth and re-epithelialization of hair follicle tissue was also observed on the 30th day. From day 21 to day 30, inflammatory cell infiltration tended to decrease. Yenilmez et al., used EYO to treat burn wounds in rats and observed the growth of collagen fibers and granulation tissue after 14 days of treatment, as well as new collagen fibers and veins on the 21st day, during which the wounds were nearly re-epithelialized [23]. Rastegar et al., applied EYO in the treatment of third-degree burns and demonstrated good re-epithelialization effects as well as the absence of scabs or scars on the wound surface [20]. The present study also demonstrated the excellent restorative effects of EYO for radiodermatitis wounds.

In the PGC112 group, there was not a large amount of matrix on the surface of the wound. There was very little steep hard skin tissue or surface scabs around the wound. The wound showed complete re-epithelialized tissue, and hair follicles were seen on the 30th day. The PGC films provided a moist environment for wound repair. As a result, large amounts of matrices were less likely to accumulate on the wound surface, and there were less hardened tissues and scabs around the wound. In addition to the good re-epithelialization of the wounds, follicle growth was noticed on the 30th day. The films were also able to limit the proliferation of fibroblasts and reduce scarring. The repaired tissue retained its smoothness and elasticity. The antibacterial properties of chitosan have also been applied for treating burn wounds [31]. Wang et al., fabricated a hydrogel from chitosan, gelatin, and honey and obtained excellent area ratios of repaired wounds [32]. Kumar et al., used chitosan-gelatin-fibrin composite bandages to treat burn wounds and 
demonstrated that chitosan was able to promote the migration of fibrins and keratinocytes to a wound [33].

\section{Days}
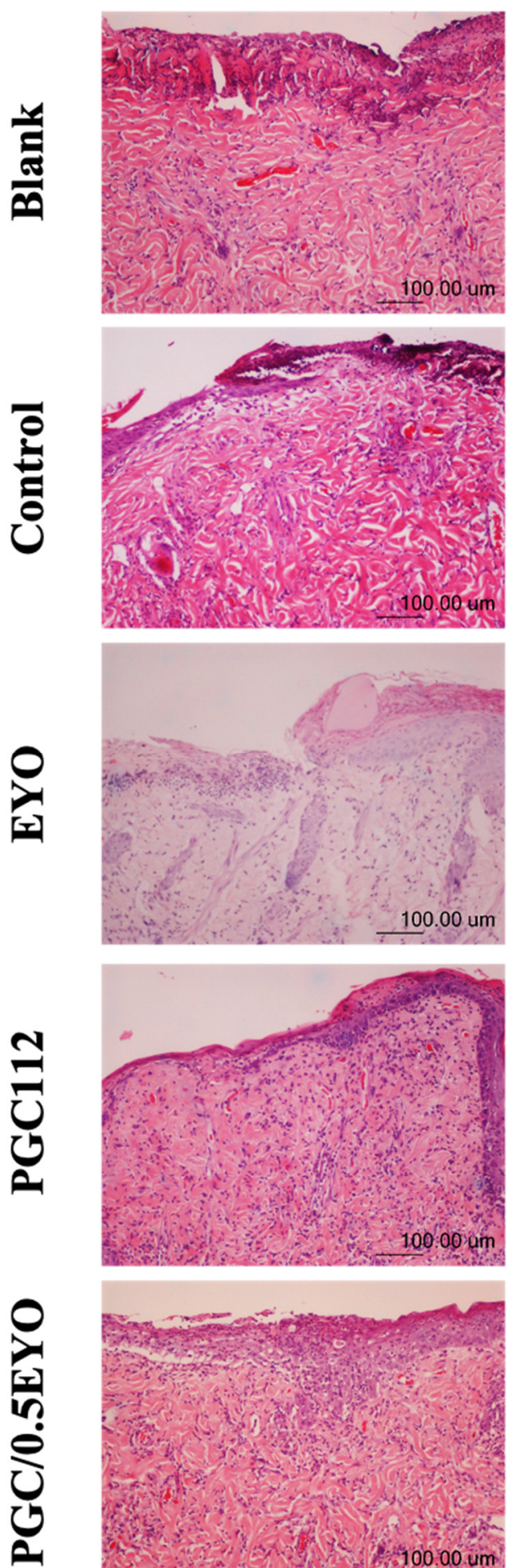

\section{Days}
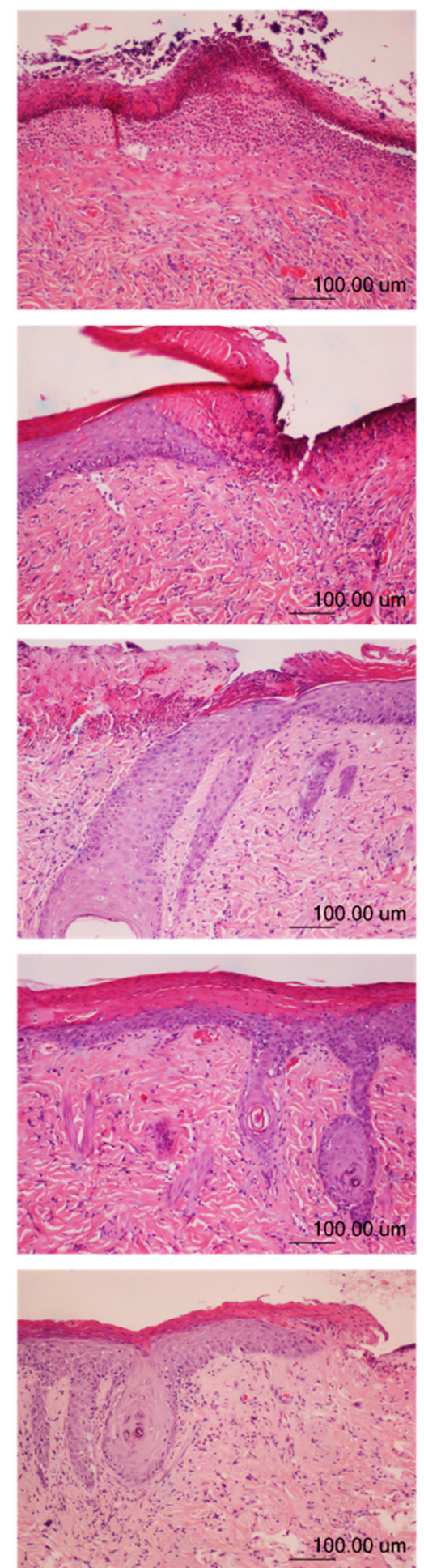

Figure 8. Histological analysis of dermatitis wound by H \& E staining after 21 days and 30 days. 
The results of the PGC/0.5EYO group were similar to those of the PGC112 group. From day 21 to day 30, the infiltration of inflammatory cells was reduced. Collagen fiber deposition, angiogenesis, granulation tissue, and hair follicle formation were observed. The new epithelial tissue covered most of the wound surface, which was a good wound closure effect. The PGC-EYO group had the best wound healing results and the smallest wound area among all the groups, as this dressing offers a moist environment along with the EYO's function of accelerating wound closure. The stained slices showed a decrease in inflammatory cell infiltration and the presence of collagen deposits, as well as the formation of new blood vessels, granulation tissue, and follicles. New epithelial cells had indeed covered a large section of the wound, resulting in good wound closure. Shaw et al., reported that the $3 \mathrm{M}^{\mathrm{TM}}$ Cavilon ${ }^{\mathrm{TM}}$ no-sting barrier films mainly protect the irradiation site against friction from fabrics and are able to delay the occurrence of pruritus. However, steroids and other anti-inflammatory drugs should be used for the treatment of hyperemia and damaged tissue [30]. EYO can reduce the production of inflammatory factors, stimulate cell migration, and promote wound closure acceleration [29]. Therefore, the groups in which EYO were used did not have excessive scabs, and inflammatory cell infiltration had reduced between the 21st and the 30th day. Follicle tissue growth and re-epithelialization was noticed on the 30th day.

\subsubsection{Immunochemical Staining Observation}

Macrophages, labeled by the CD68 antibody, are among the most important inflammatory cells involved in wound repair. Neutrophils play the most prominent role in the early stages of inflammation, while macrophages dominate the later stages when they enter damaged tissue and secrete various growth factors while activating inflammatory cell infiltration, engulfing pathogens and promoting immune responses. Neutrophils that take part in the phagocytosis of apoptotic cells reduce the number of neutrophils infiltrated in the tissue. Delayed macrophage aggregation would result in excessive levels of neutrophils that prolong inflammation and delay wound healing [34]. Therefore, a decrease in CD68 markers indicates that a wound is starting to heal. CD68 immunostaining images were obtained on the 21st and 30th day of each group (Figure 9a). The area of CD68 markers in the skin tissue of each group was calculated (Figure 9b). The result show that the area of CD68 in the Blank group increased with the increase of days, indicating that the inflammatory response was still going on, while the area of CD68 in the other groups decreased with the increase of days. However, the PGC/0.5EYO group showed the best anti-inflammatory effect. Research has demonstrated that EYO can reduce up to $70 \%$ of the interleukins released by stimulated lymphocyte, thereby affecting the speed of wound repair, reducing widespread inflammatory responses and promoting wound healing [29]. The chitosan in the films stimulates the production of ECM and enables macrophages to produce transforming growth factors. Chitosan also stimulates macrophages to produce platelet-derived growth factor (PDGF) and assists in angiogenesis [35]. Therefore, the biological reactions between PGC and EYO in the PGC/EYO group could reduce most interleukin-induced inflammations [29] while stimulating the proliferation of fibroblasts and epithelial cells [15,33], which have significant effects for radiodermatitis wound healing. 

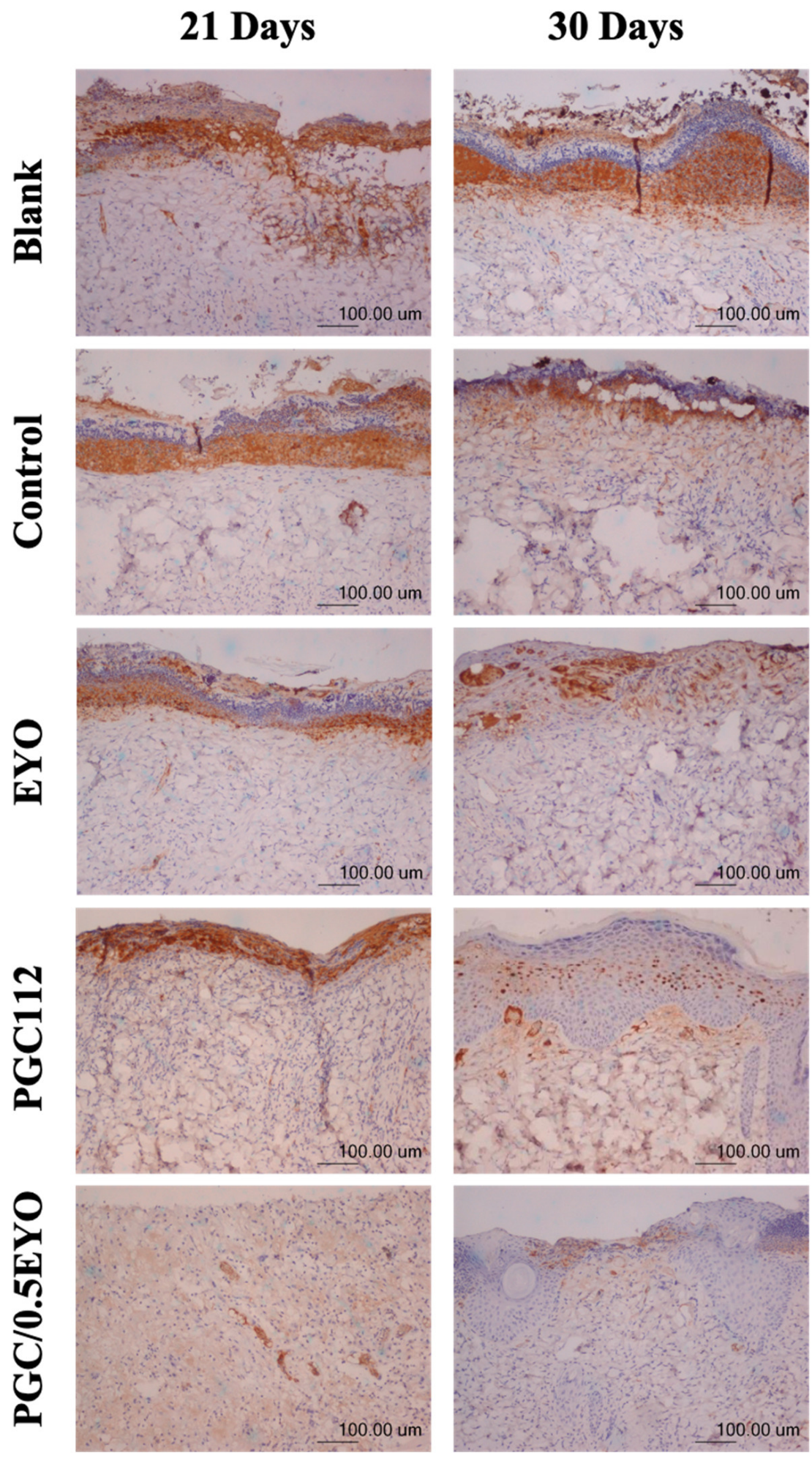

(a)

Figure 9. Cont. 


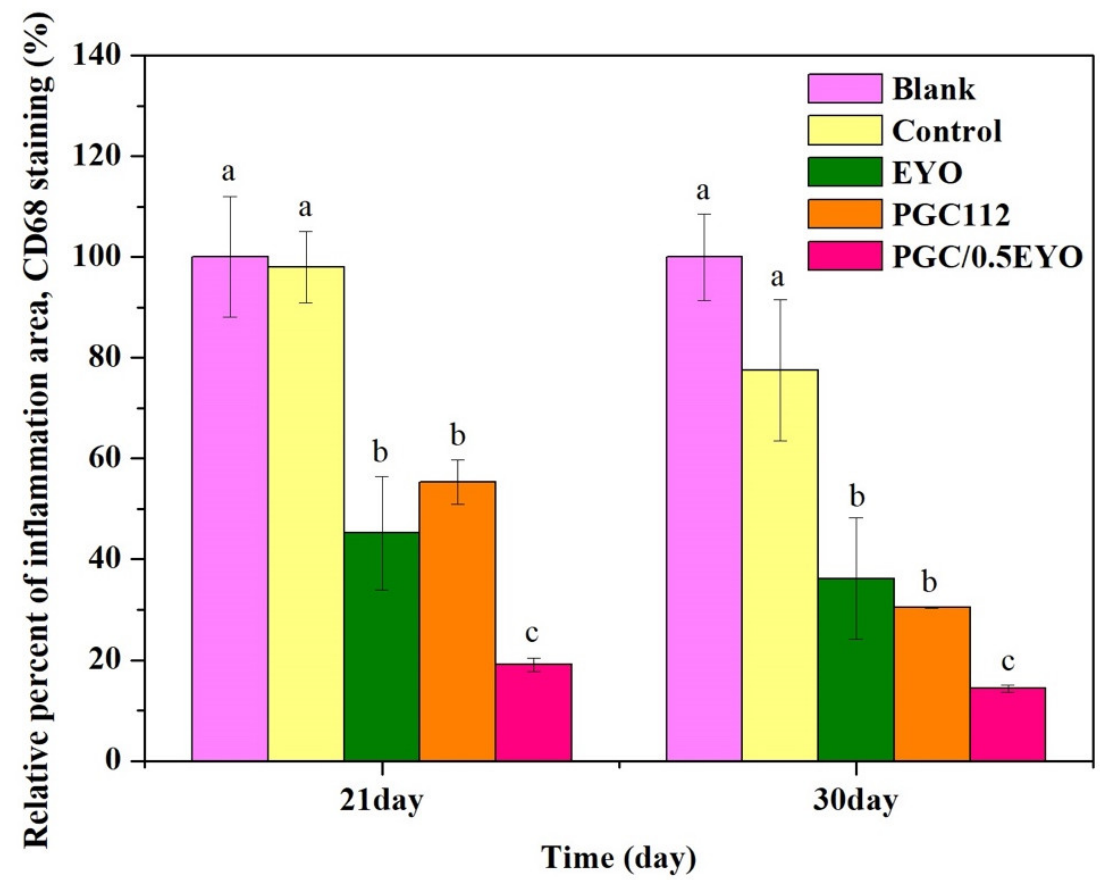

(b)

Figure 9. (a) Immunohistochemistry analysis of dermatitis wound using CD68 antibody (macrophage marker) after 21 days and 30 days. (b) The area of CD68 marker of each skin tissue. Means with different letters were significantly different $(p<0.05$, mean $\pm \mathrm{SD}, n=5)$.

\section{Conclusions}

The skin is the first barrier against radiation exposure, and skin damage can progress several days to several years after exposure [36]. The goal of radiotherapy is to completely deliver a dose of ionizing radiation to eliminate tumor cells through ionizing radiation and reduce the damage to surrounding healthy tissues [36]. RSI is a frequent complication of radiotherapy. Severe cases can affect the patient's disease treatment and quality of life [37]. Ertekin et al., and Doctrow et al., regarding prevention and treatment of RSI, used zinc sulphate and synthetic superoxide dismutase/catalase mimetic EUK-207, respectively $[36,38]$. This study was to evaluate the effect of EYO on rats using an RSI model, and to study its effects on the delay of radiation-induced skin injury, including impaired wound healing. The results showed that the PGC112 film displayed desirable water absorption and soft and tough mechanical properties, and also had an appropriate biodegradability. The addition of EYO will not affect the original mechanical properties of the film material and will significantly reduce the area of radiodermatitis wounds. PGC/EYO films can assist in delaying the onset of radiodermatitis. The composite film PGC112 blended with EYO has good biocompatibility and is conducive to fit with the wound. EYO microspheres coated in the substrate can be released slowly and were not diluted by body fluids, and they did not quickly degrade when in contact with tissues. Comparing the results of only smear EYO and /0.5EYO film from in vivo tests, the researchers found that the film had a better skin repair effect and mild inflammation reaction in the initial stage. The PGC/EYO dressings were able to absorb interstitial fluid, provide a moist environment for wound repair, decrease matrix accumulation, and promote cell migration and proliferation. In addition, the EYO in the dressings can promote the re-epithelialization of radiodermatitis wounds, thus demonstrating the developmental potential of polymer PGC/0.5EYO films. It is expected that PGC/0.5EYO films can be applied in clinical radiotherapy for effective wound repair and wound pain alleviation. 
Author Contributions: Conceptualization, S.-R.H. and Y.-C.H.; methodology, S.-R.H.; validation, J.-Y.K.; formal analysis, S.-C.H.; investigation, S.-R.H.; resources, C.-J.C.; data curation, S.-R.H.; writing—original draft preparation, Y.-C.H.; writing—review and editing, C.-M.T.; project administration, C.-J.C. All authors have read and agreed to the published version of the manuscript.

Funding: This research received no external funding.

Institutional Review Board Statement: The study was conducted according to the guidelines of the Declaration of Helsinki and approved by the animal experimentation committee at the Central Taiwan University of Science and Technology (Taichung, Taiwan) (Approve number 107-CTUST-011, 14 February 2019).

Informed Consent Statement: Not applicable.

Data Availability Statement: No data to report.

Conflicts of Interest: The authors declare no conflict of interest.

\section{References}

1. Singh, M.; Alavi, A.; Wong, R.; Akita, S. Radiodermatitis: A review of our current understanding. Am. J. Clin. Dermatol. 2016, 17, 277-292. [CrossRef] [PubMed]

2. Fisher, J.; Scott, C.; Stevens, R.; Marconi, B.; Champion, L.; Freedman, G.M.; Asrari, F.; Pilepich, M.; Gagnon, J.D.; Wong, G. Randomized phase III study comparing Best Supportive Care to Biafine as a prophylactic agent for radiation-induced skin toxicity for women undergoing breast irradiation: Radiation Therapy Oncology Group (RTOG) 97-13. Int. J. Radiat. Oncol. Biol. Phys. 2000, 48, 1307-1310. [CrossRef]

3. D'haese, S.; Van Roy, M.; Bate, T.; Bijdekerke, P.; Vinh-Hung, V. Management of skin reactions during radiotherapy in Flanders (Belgium): A study of nursing practice before and after the introduction of a skin care protocol. Eur. J. Oncol. Nurs. 2010, 14, 367-372. [CrossRef] [PubMed]

4. $\quad$ Richardson, J.; Smith, J.E.; McIntyre, M.; Thomas, R.; Pilkington, K. Aloe vera for preventing radiation-induced skin reactions: A systematic literature review. Clin. Oncol. 2005, 17, 478-484. [CrossRef]

5. Momm, F.; Weißenberger, C.; Bartelt, S.; Henke, M. Moist skin care can diminish acute radiation-induced skin toxicity. Strahlenther. Onkol. 2003, 179, 708-712. [CrossRef]

6. Wang, J.; Li, Y.; Gao, Y.; Xie, Z.; Zhou, M.; He, Y.; Wu, H.; Zhou, W.; Dong, X.; Yang, Z. Cinnamon oil-loaded composite emulsion hydrogels with antibacterial activity prepared using concentrated emulsion templates. Ind. Crop. Prod. 2018, 112, 281-289. [CrossRef]

7. Yogi, V.; Singh, O.; Mandloi, V.; Ahirwar, M. Role of topical aloe vera gel in the recovery of high-grade, radiation-induced dermatitis. Clin. Cancer Investig. J. 2018, 7, 167. [CrossRef]

8. Heggie, S.; Bryant, G.P.; Tripcony, L.; Keller, J.; Rose, P.; Glendenning, M.; Heath, J. A phase III study on the efficacy of topical aloe vera gel on irradiated breast tissue. Cancer Nurs. 2002, 25, 442-451. [CrossRef]

9. Rashid, R.; Lim, N.S.J.; Chee, S.M.L.; Png, S.N.; Wohland, T.; Raghunath, M. Novel use for polyvinylpyrrolidone as a macromolecular crowder for enhanced extracellular matrix deposition and cell proliferation. Tissue Eng. Part C Methods 2014, 20, 994-1002. [CrossRef]

10. Li, J.; Zivanovic, S.; Davidson, P.A.; Kit, K. Characterization and comparison of chitosan/PVP and chitosan/PEO blend films. Carbohydr. Polym. 2010, 79, 786-791. [CrossRef]

11. Salles, T.H.C.; Lombello, C.B.; d'Ávila, M.A. Electrospinning of gelatin/poly (vinyl pyrrolidone) blends from water/acetic acid solutions. Mater. Res. 2015, 18, 509-518. [CrossRef]

12. Serafim, A.; Petre, D.G.; Moraru, L.; Cioflan, H.E.; Vasile, E.; Mastalier-Manolescu, B.; Petrutescu, M.; Stancu, I.C. Gelatin-PVP hydrogels with potential skin grafts applications. Key Eng. Mater. 2015, 638, 38-46. [CrossRef]

13. Ran, W.; Ma, H.; Li, M. In Vitro and In Vivo Studies of Polyvinyl Pyrrolidone-Coated Sparfloxacin-Loaded Ring Contact Lens to Treat Conjunctivitis. J. Pharm. Sci. 2020, 109, 1951-1957. [CrossRef]

14. El-Aassar, M.; Ibrahim, O.M.; Fouda, M.M.; Fakhry, H.; Ajarem, J.; Maodaa, S.N.; Allam, A.A.; Hafez, E.E. Wound dressing of chitosan-based-crosslinked gelatin/polyvinyl pyrrolidone embedded silver nanoparticles, for targeting multidrug resistance microbes. Carbohydr. Polym. 2021, 255, 117484. [CrossRef]

15. Risbud, M.; Hardikar, A.; Bhonde, R. Growth modulation of fibroblasts by chitosan-polyvinyl pyrrolidone hydrogel: Implications for wound management? J. Biosci. 2000, 25, 25-30. [CrossRef]

16. Janvikul, W.; Uppanan, P.; Thavornyutikarn, B.; Krewraing, J.; Prateepasen, R. In vitro comparative hemostatic studies of chitin, chitosan, and their derivatives. J. Appl. Polym. Sci. 2006, 102, 445-451. [CrossRef]

17. Neumann, P.; Zur, B.; Ehrenreich, Y. Gelatin-based sprayable foam as a skin substitute. J. Biomed. Mater. Res. 1981, 15, 9-18. [CrossRef]

18. Lan, G.; Lu, B.; Wang, T.; Wang, L.; Chen, J.; Yu, K.; Liu, J.; Dai, F.; Wu, D. Chitosan/gelatin composite sponge is an absorbable surgical hemostatic agent. Colloids Surf. B Biointerfaces 2015, 136, 1026-1034. [CrossRef] 
19. Xiong, S.; Gong, Q.-F.; Ning, X.-X. The research progress of egg yolk. J. Gannan Med Univ. 2014, 34, 313-320.

20. Rastegar, F.; Azarpira, N.; Amiri, M.; Azarpira, A. The effect of egg yolk oil in the healing of third degree burn wound in rats. Iran. Red Crescent Med J. 2011, 13, 739.

21. Zhao, Y.; Zhang, Y.; Liu, X.; Kong, H.; Wang, Y.; Qin, G.; Cao, P.; Song, X.; Yan, X.; Wang, Q. Novel carbon quantum dots from egg yolk oil and their haemostatic effects. Sci. Rep. 2017, 7, 1-8. [CrossRef] [PubMed]

22. Klinkesorn, U. The role of chitosan in emulsion formation and stabilization. Food Rev. Int. 2013, 29, 371-393. [CrossRef]

23. Yenilmez, E.; Başaran, E.; Arslan, R.; Berkman, M.; Güven, U.; Baycu, C.; Yazan, Y. Chitosan gel formulations containing egg yolk oil and epidermal growth factor for dermal burn treatment. Die Pharm. Int. J. Pharm. Sci. 2015, 70, 67-73.

24. Rodil, A.; Laca, A.; Paredes, B.; Rendueles, M.; Meana, Á.; Díaz, M. Gels prepared from egg yolk and its fractions for tissue engineering. Biotechnol. Prog. 2016, 32, 1577-1583. [CrossRef]

25. El Achaby, M.; Essamlali, Y.; El Miri, N.; Snik, A.; Abdelouahdi, K.; Fihri, A.; Zahouily, M.; Solhy, A. Graphene oxide reinforced chitosan/polyvinylpyrrolidone polymer bio-nanocomposites. J. Appl. Polym. Sci. 2014, 131, 41042. [CrossRef]

26. Wahba, M.I. Enhancement of the mechanical properties of chitosan. J. Biomater. Sci. Polym. Ed. 2020, 31, 350-375. [CrossRef]

27. Huang, M.-Y.; Huang, J.-J.; Chai, C.-Y.; Chen, S.-H.; Kuo, M.-P.; Lin, C.-C. The reduction effect of extracts of soybean seeds on acute radiation dermatitis. Fooyin J. Health Sci. 2010, 2, 21-25. [CrossRef]

28. Al-Abayaji, M.A. Extraction and Determination of Iraqi Boiled Egg Yolk Constituents, and Characterization of Lecithin. J. Coll. Basic Educ. 2015, 20, 49-56.

29. Bereiter-Hahn, J.; Bernd, A.; Beschmann, H.; Eberle, I.; Kippenberger, S.; Rossberg, M.; Strecker, V.; Zöller, N. Cellular responses to egg-oil (charismon@). Acta Med. 2015, 57, 41-48. [CrossRef]

30. Shaw, S.-Z.; Nien, H.-H.; Wu, C.-J.; Lui, L.T.; Su, J.-F.; Lang, C.-H. 3M Cavilon No-Sting Barrier Film or topical corticosteroid (mometasone furoate) for protection against radiation dermatitis: A clinical trial. J. Formos. Med Assoc. 2015, 114, 407-414. [CrossRef]

31. Dai, T.; Tanaka, M.; Huang, Y.-Y.; Hamblin, M.R. Chitosan preparations for wounds and burns: Antimicrobial and wound-healing effects. Expert Rev. Anti-Infect. Ther. 2011, 9, 857-879. [CrossRef]

32. Wang, T.; Zhu, X.-K.; Xue, X.-T.; Wu, D.-Y. Hydrogel sheets of chitosan, honey and gelatin as burn wound dressings. Carbohydr. Polym. 2012, 88, 75-83. [CrossRef]

33. Kumar, P.S.; Praveen, G.; Raj, M.; Chennazhi, K.; Jayakumar, R. Flexible, micro-porous chitosan-gelatin hydrogel/nanofibrin composite bandages for treating burn wounds. RSC Adv. 2014, 4, 65081-65087. [CrossRef]

34. Koh, T.J.; DiPietro, L.A. Inflammation and wound healing: The role of the macrophage. Expert Rev. Mol. Med. 2011, 13, e23. [CrossRef]

35. Krzyszczyk, P.; Schloss, R.; Palmer, A.; Berthiaume, F. The role of macrophages in acute and chronic wound healing and interventions to promote pro-wound healing phenotypes. Front. Physiol. 2018, 9, 419. [CrossRef]

36. Ertekin, M.V.; Tekin, S.B.; Erdoğan, F.; Karslioğlu, I.; Gepdiremen, A.; Sezen, O.; Balci, E.; Gündoğdu, C. The effect of zinc sulphate in the prevention of radiation-induced dermatitis. J. Radiat. Res. 2004, 45, 543-548. [CrossRef]

37. Wang, Y.; Tu, W.; Tang, Y.; Zhang, S. Prevention and treatment for radiation-induced skin injury during radiotherapy. Radiat. Med. Prot. 2020, 1, 60-68. [CrossRef]

38. Doctrow, S.R.; Lopez, A.; Schock, A.M.; Duncan, N.E.; Jourdan, M.M.; Olasz, E.B.; Moulder, J.E.; Fish, B.L.; Mäder, M.; Lazar, J. A synthetic superoxide dismutase/catalase mimetic EUK-207 mitigates radiation dermatitis and promotes wound healing in irradiated rat skin. J. Investig. Dermatol. 2013, 133, 1088-1096. [CrossRef] 